\title{
Triangulation, respondent validation, and democratic participation in mixed methods research
}

Harry Torrance, Manchester Metropolitan University, UK ${ }^{1}$

\begin{abstract}
$\underline{\text { Abstract }}$
Over the last ten years or so, the 'Field' of 'Mixed Methods Research' (MMR) has increasingly been exerting itself as something separate, novel and significant, with some advocates claiming paradigmatic status. Triangulation is an important component of mixed method designs. Triangulation has its origins in attempts to validate research findings by generating and comparing different sorts of data, and different respondents' perspectives, on the topic under investigation. Respondent validation has sometimes been included in such processes, but it is an element which has not attracted significant attention from the MMR community. The article argues that attention to respondent validation is a significant issue for methodological debate and that it should be an important aspect of the development of democratic participation in mixed methods research.
\end{abstract}

\section{Introduction}

Mixing methods in social research and program evaluation has a long and in many respects unremarkable history. Mixing methods was simply regarded as the proper way to do good research. No single method could afford a complete purchase on the topic under study (Bryman, 1988: Denzin, 1970). Evaluations have routinely employed a range of methods to investigate the site-based specifics of program interpretation and adoption, alongside more general surveys of implementation and outcomes across sites (Greene, et.al. 1989). Even 'classic' participant observation studies such as Street Corner Society (Whyte, 1943) or Boys in White (Becker, et.al. 1961) involved a good deal of unstructured and semi-structured interviewing, alongside extended periods of observation, in a variety of different settings, as the fieldworkers attempted to check the validity of their emerging understandings of what was going on. As Martyn Denscombe (2008, p. 274) recently noted in this journal, there is much "evidence to suggest that for a long time the use of mixed methods has been going on in the background without being celebrated or heralded as part of a new paradigm".

And yet, over the last ten years or so, the 'Field' of 'Mixed Methods Research' (capital M, capital M, capital R) has increasingly been exerting itself as something separate, novel, and significant, such that proponents such as Tashakkori and Teddlie (2003) claim: "Mixed methods research has evolved to the point where it is a separate methodological orientation

\footnotetext{
${ }^{1}$ Published as Torrance H. (2012) Triangulation, respondent validation, and democratic participation in mixed methods research Journal of Mixed Methods Research 6, 2, 111-123.
} 
with its own worldview, vocabulary and techniques" (p. x). Johnson et.al (2007) argue that "Mixed methods research...is becoming increasingly...recognised as the third major research approach or research paradigm...We currently are in a three... research paradigm world, with quantitative, qualitative and mixed methods research all thriving and co-existing" (pp. 112 \& 117 , original emphasis).

More recently, as such views have been challenged, interrogated and augmented, the arguments have been modified, and the second edition of the Handbook of Mixed Methods Research recognises that mixing methods in research design encompasses a wide range of approaches to and interpretations of mixed methods work (Tashakkori \& Teddlie 2010). The claim to a distinct third paradigm is left open, not least because other MMR advocates have criticised the whole notion of paradigms somehow driving and determining research methods and have argued instead for a more grounded and pragmatic approach to understanding what researchers actually do, and how different approaches are actually combined in action (Christ, 2009; Greene, 2008; Harrits, 2011; Morgan; 2007). But if the case for a new paradigm has not yet been agreed, in some ways the second edition of the Handbook of Mixed Methods Research delineates an even more ambitious and all-encompassing project by proposing a set of nine characteristics that define "the third methodological community" (Tashakkori \& Teddlie 2010, p.11), along with claims that new forms of data integration and synthesis are emerging within this community and are distinctive to this community (see for example the "List of Data Analysis Terms Indigenous to Mixed Methods Research", Tashakkori and Teddlie 2010 p.20, my emphasis).

There are many reasons, intellectual, material and political, why claims might be made that a particular approach to research is novel and/or better than that which has gone before. I do not intend to explore this matter further here (Torrance (2011) for such a discussion). But it does seem that 'Mixed Methods Research' (MMR) is being presented as something new and distinct; a new and better form of science; a more complex approach to research designed to address the more complex problems that social research now faces (Caracelli, 2006; Creswell, et. al. 2011). However, a major debate is emerging within this 'third community', with respect to whether or not MMR is 'just' a new form of science, a better technical fix for getting a purchase on social policy issues, or a new form of science with an explicit orientation towards valuing complexity and diversity, including critical engagement with policy and the pursuit of social justice (Greene, 2007, 2009; Hesse-Biber 2010a, 2010b; 
Mertens, 2007, Mertens, et. al. 2010). This paper is written as a contribution to this emerging debate, and it is argued that the views of research respondents should feature more centrally in mixed methods research designs and the co-construction of research knowledge. Several contributors to the mixed methods literature argue strongly for the development of iterative, self reflective research practices which align with action research and new forms of 'user engagement' with public service provision (Christ, 2009, 2010; Mertens, et. al. 2010). Yet the specific methods identified, including use of focus groups and/or more traditional forms of qualitative research such as interviewing, still leave the research agenda and the validity of data analysis largely in the hands of the researchers. Morgan (2007, p. 73) summarizes the issue very clearly when he states:

I find it helpful to think of Qualitative Research as research that emphasises an inductive-subjective-contextual approach, whereas Quantitative Research emphasises a deductive-objective-generalising approach. Where we encounter problems is by treating these broad tendencies as absolute defining characteristics for these two different approaches...the pragmatic [MMR] approach offers an effective alternative through its emphasis on the abductive-intersubjective-transferable aspects of our research [my emphasis].

Thus all three "approaches" to social research emphasise the perspective and remain under the control of the researcher. Irrespective of approach, it is "our research". The "intersubjective-transferable" elements of Morgan's "pragmatic" approach refer to communication within research teams and across methods, not across the researcherresearched boundary, although they could and, I will argue, should. A key issue for contemporary social research, including mixed methods research, is what might be the changing role of science in the construction of social knowledge, and indeed what might be the role of research participants in the construction of scientific knowledge. It is this element of contemporary social research that I wish to raise and address in this paper.

\section{$\underline{\text { Triangulation }}$}

At root it can be argued that the core justificatory principle underpinning mixed method approaches is that of triangulation. To reiterate, no single method is likely to afford a comprehensive account of the phenomenon under investigation, thus two or more methods are employed to bring to bear different intellectual tools on the task at hand. The assumption is that different perspectives can be generated which will give a fuller and more informative picture of what is going on: such fuller pictures will be more rounded, nuanced and valid than 
that produced by a single method. It may be of course that different data sources generate discrepant accounts, but such a possibility has often been interpreted as simply warranting further investigation. Discrepant accounts are treated as interesting but puzzling findings that inform us that our original understandings have been inadequate and thus require further data to be gathered and further interpretive activity to be undertaken (Patton, 1980; Mathison, 1988). An underlying implication of such research practice is that social scientists can indeed generate accounts of social phenomena which provide more insight into issues and problems than might routinely be the case, and moreover, that such accounts can be improved by social scientists gathering more, and better, information.

Denzin (1970, $2^{\text {nd }}$ ed. 1978) provided the first in-depth discussion of triangulation in The Research Act, a very explicitly mixed methods research text: "Advocating triangulation, or the combination of methodologies in the study of the same phenomenon, has been a basic theme of this book" (Denzin 1978, p.291).

Denzin $(1970,1978)$ delineated four essential aspects of triangulation:

a) Triangulation of data - i.e. different sources, accessed over time;

b) Of investigators - i.e. use of teams if possible;

c) Of method - i.e. observation, interview, survey, etc (and interestingly, given current debates about 'Scientific Research in Education' (NRC 2002) and Denzin's (2010) position on them, the book includes a chapter on experiments);

d) And of theory - i.e. the bringing to bear of different theoretical perspectives on the data in order to generate different interpretive accounts: "By combining multiple observers, theories, methods and data sources, sociologists can hope to overcome the intrinsic bias that comes from single-method, single-observer, single-theory studies"(Denzin 1978 p. 307).

Such arguments attracted criticisms, especially from interactionists who objected to the implication that a single social reality could be apprehended by a more all-encompassing and integrated social science (Fielding \& Fielding, 1986; Silverman, 1985). In turn the third edition of The Research Act acknowledged such criticisms and conceded that the same phenomenon could not simply be isolated and measured by different means, nor a single valid account produced; rather different accounts could be generated and compared to produce a better understanding of the phenomenon under study: 
It is erroneous to...imply that the same unit can be measured...[ ]...The goal of multiple triangulation is a fully grounded interpretive research approach...In-depth understanding, not validity, is sought in any interpretive study

(Denzin 1989 pp. $244 \&$ 246).

Three crucial issues lie at the heart of this debate, and in many respects still lie at the heart of any debate over social science research methods:

First, how do researchers link different kinds of data in order to generate better understanding - for all the claims of new forms of data integration and synthesis that are currently being made by MMR advocates, it is still not clear exactly what sorts of integrative thinking processes really afford such outcomes (Bergman 2008).

Second, how can such integration take place and better understandings be generated, without implying that a single 'true' ("valid") account can (and should) be produced - the problem here, of course, is that the claim to a single 'true' account implies that 'untrue' accounts be discarded; but this would privilege science above politics and while we might agree that eradicating disease is a worthwhile pursuit, eradicating social beliefs and practices is a rather more contentious activity.

Third, whose account of the phenomenon under study should be privileged - that of the scientist (Denzin's "sociologist") or that of the research participants under investigation?

\section{Respondent validation}

One element of triangulation, albeit an element that is not discussed extensively in the literature, is that of respondent validation or member checks. Respondent validation involves research participants responding either to forms of initial data, e.g. transcripts of interviews, or observations of activities, in order to check them for accuracy, or to first drafts of interpretive reports to respond, again, to their accuracy, but also to the interpretive claims that are being made (Bloor, 1978; Lincoln \& Guba, 1985). Researchers can also involve research participants in both processes. They can check the accuracy of initial data gathered, including whether or not participants have more to add to the transcript of their interview(s) when they have the opportunity to reflect at more length on the topic under investigation. And,they can be asked to comment on whether the emerging account is recognised as a fair and reasonable reflection of the situation as they understand it. Individual research respondents can be involved in both processes throughout - necessitating the return of transcripts and/or other data - and then the circulation for comment of first draft interpretive accounts. Sometimes all individual respondents are only involved at the data checking stage, and then key 
stakeholders are invited to meetings to discuss the emerging draft report. The process often involves new evidence coming to light and draft reports being modified. Disagreements are sometimes accommodated by 'dissenting minority reports' being added as postscripts to the main report (Walker,1974; Bloor, 1978; Lincoln \& Guba, 1985).

'Member checking' or 'member checks' tends to be the term used for this process in US qualitative and mixed methods texts (e.g. Creswell, 2003; Lincoln \& Guba, 1985, Teddlie \& Tashakkori, 2009); respondent validation seems to be more associated with UK sociology (e.g. Bloor, 1978; Fielding \& Fielding, 1986). However, even when mixed methods texts do mention member checks, it tends to be as a limited reference to one element of a qualitative approach to interpretive validation, rather than as a core issue for the mixed methods field; i.e. as a relatively minor element of qualitative procedures and techniques, rather than as a core issue for social science research per se (Creswell, 2003, p. 196; Creswell \& Plano Clark, 2007, p. 134; Teddlie \& Tashakkori, 2009, p. 213). Jang et al. (2008) provide one example of this approach when they involve school principals in checking draft reports about their schools. The most recent new edition of the Handbook Mixed Methods Research (Teddlie \& Tashakkori, 2010), which treats philosophical as well as methodological issues, has no reference to member checks or respondent validation in the subject index.

Having said this, it is also the case that some mixed methods researchers are increasingly acknowledging the importance of engaging with the views and perspectives of research participants in order to represent these perspectives as fully and validly as possible (Christ 2009, 2010, Mertens et. al. 2010). Whether or not such engagement constitutes respondent validation remains a moot pointFor example, Christ $(2009,2010)$ advocates an action research approach to "co-construct knowledge between research-teacher and the participants through reflection" (Christ, 2010, p. 664). However, it is not clear that this involves validating the accuracy of data and reports in the ways described above. Indeed he later locates the validity of his study in "multiple analyst triangulation....and...expert audit... when an expert program evaluator, independent of the study, examined emergent themes..." (Christ, 2010, p. 665). So, in this mixed methods design, validity resides in the judgement of an "expert", rather than in negotiation with participants.

Respondent validation derives from both theoretical and ethical considerations. Theoretically, symbolic interactionists and ethnomethodologists have an interest in how 
social groups define and maintain their boundaries, how members come to 'know' and recognise themselves and produce coherent accounts of their daily lives. Disinterring such knowledge is the central concern of interpretive sociology:

...if the scholar wishes to understand the action of people it is necessary for him to see their objects as they see them...people act towards things on the basis of the meaning that these things have for them, not on the basis of the meaning that these things have for the outside scholar (Blumer, 1969, p. 51).

For the most part, such theoretical interests have been pursued by getting close to social groups and producing extensive descriptive accounts of their activities and understandings. However it is arguable that such accounts nevertheless remain those of the "outside scholar" and that it is important to go on to ask research participants about the accuracy, fairness and validity of such accounts.

Furthermore, even if the scholar's account might be accepted as accurate, there are many ethical arguments for insisting that research respondents should at least have sight of reports before they are published, if not a right to respond to such reports. Carolyn Ellis (1995) provides a graphic account of the pain caused to her respondents and to herself by publishing an ethnography of a fishing community which had come to regard her (at least by her own account) as a friend. She published her book of the research without the community's knowledge or consent. For them, she had betrayed their confidences. For herself, as a middle class academic researching a working class rural community, she had taken-for-granted the privileged scientific status of her work and had "othered" them (pp. 69 and 86). Social researchers have traditionally addressed (or perhaps we might more accurately say ignored) ethical issues by assuming that reporting anonymously protected the communities under study. But participants can often recognise themselves, or perhaps worse, think that they recognise themselves and others, and make judgements accordingly. In Ellis's case, the ethical also shades back into the ontological: would people have spoken in the same way if they had known the material might be published, and if not, which account of social reality would be the more valid (also Duncier 2001).

There are arguments against the use of respondent validation. Individuals within a social setting may have a partial view (in both senses of the word) of the collectivity's activities. Some individuals may have more power than others to shape the collectivity's view of itself and of any emergent research report. Moreover, as Fielding and Fielding (1986, 
p. 43) note: "There is...no reason to assume that members have privileged status as commentators on their own actions...”. But if not members, then who? Researchers, by the very nature of their investigative activities, have 'access all areas' in ways which any individual collectivity member probably does not. So a researcher's outsider account, while it may be more comprehensive, and perhaps more 'objective' in the sense that they do not have particular insider axes to grind, will still not be describing something that is actually true for any individual within the social setting, i.e. something that 'really' exists in an ontological sense. The account is the researcher's construction.

As the above discussion implies, respondent validation is usually associated with qualitative approaches to research but the issues raised are equally relevant to quantitative and mixed methods approaches, especially in the context of program evaluation when complete anonymity of respondents is unlikely to be achieved and key decisions about people's lives may rest on the results of the evaluation. In the context of evaluative studies even surveys and experiments will likely involve known experimental sites with key participants identifiable and exposed to critical scrutiny. I will return to these more general issues of the politics and ethics of evaluation below, but for the moment I want to consider the role of qualitative approaches in mixed methods research designs and in turn the role that respondent validation might play in mixed methods research designs.

\section{The role of qualitative research in mixed methods designs}

Arguments about mixed methods research as a distinct 'paradigm' seem to have their origins in mixed methods approaches to applied research activities including social program evaluation, particularly in fields such as education and health care. The need to generate overviews of program implementation and impact (or lack of it) along with more detailed understandings of the experience of participants and why things seemed to work in one setting, but not in another, led to designs involving experiments, surveys and case studies. Jennifer Greene et. al. (1989) drew much of this work together in an influential review article, but also noted that:

In many of the evaluations...that we reviewed there was a paramedic quality to the qualitative component...qualitative data often appeared in the emergency room of report writing as a life-saving device to resuscitate what was either a failed program or a failed evaluation (p. 269) 
Or, one might add, both! The qualitative data was needed to explain why there was no significant difference between experimental and control groups.

However, the use of the term 'paramedic' is perhaps even more illuminating than was originally intended by Greene and colleagues, since it indicates the vital but nevertheless subservient role that qualitative data often fulfils in mixed methods approaches. Hesse-Biber (2010a, p. 457) argues that the field of MMR still leans:

toward a more positivist methodological orientation...[and] employs qualitative data as 'handmaiden' or 'second best' to the quantitative data...to illustrate quantitative results...to provide narrative examples of the conclusions already reached.

Others might disagree, with much recent discussion valuing the strengths that qualitative research can bring to mixed methods designs, the importance of conceiving of research approaches as a continuum rather than a binary categorisation, and indeed the developing dialogue around valuing diversity of approach and primacy of the research question (Christ, 2010; Creswell, 2010; Niglas, 2010).

Nevertheless subservience does seem to be apparent in the context of governmentsponsored evaluation studies, when arguing for the inclusion of qualitative methods is often predicated on what detail it can supply to flesh out the bones of a survey or experiment in the context of a demand for empirical evidence of 'what works'. Researchers and evaluators have highlighted this in the field of health care and nursing (e.g. Meyer, 2005; Giddings, 2006), and such an orientation is also apparent in education and other social program areas. Thus for example, Valerie Caracelli (2006) reports several instances in an article written from the perspective of the US Government Accountability Office and which argues for the inclusion of qualitative methods alongside the use of surveys and randomised controlled field trials "to assure contextual understanding" (p. 84). She states that: "Recently, there has been an acknowledgement about how ethnographic studies can inform agency actions and how it can be used to study culture in organisations" (p.87).

A recent UK Cabinet Office report is particularly interesting and illuminating in this respect. Independent academics based at the National Centre for Social Research (a not-forprofit organization) were commissioned by the Strategy Unit of the Cabinet Office to produce a "framework for assessing research evidence" with respect to qualitative evaluation (Cabinet Office, 2003). The rationale seems to have been that UK government departments are 
commissioning policy evaluations in the context of the move toward evidence-informed policy and practice and that guidelines for judging the quality of qualitative approaches and methods were therefore necessary. However, one of the key quotes in the report used to justify the use of qualitative methods comes not from the epistemological or methodological literature, but from a civil servant, a government department "research manager":

I often commission qualitative research when it's about users or stakeholders and ... I want to understand ... how a user is likely to respond. ... I want to know how they see the world...it's a wonderful vehicle ... if you want to understand the motives of people. (Cabinet Office, 2003, p. 34).

So agencies and policy makers on both sides of the Atlantic value qualitative research for the insight it can provide into the "culture" of organisations and the "motives" of the people who work in them. Now, although it can certainly be argued that policy and its evaluation will benefit from being grounded in such data, it is equally the case that such evidence could be used to monitor compliance with policy rather than to evaluate it. Qualitative data could even be used to allocate blame to individuals at the local level if implementation is found to be ineffective, rather than critique policy or dissemination strategies. Evaluation requires that policy and policymakers are themselves also rendered subject to scrutiny, not that (qualitative) social research methods are simply used to provide data for the powerful. A commitment to respondent validation might provide some counterbalancing movement to these very centralising tendencies.

Some have argued not just for the inclusion of qualitative methods in mixed method designs, but for developing a more qualitatively driven approach to MMR - attending to the values and social justice aspirations of more radical qualitative approaches to research, in addition to the techniques. It is argued that the attention to complexity that qualitative approaches afford, and to the perspectives of participants, should place such approaches at the forefront of any research design. For example, Hesse-Biber (2010a) argues that qualitative approaches can play a far stronger role in MMR designs and reviews several studies which, she claims, give equal weight to the qualitative and quantitative element of the investigation in various forms of "sequential exploratory" (p.459) and "sequential explanatory" (p. 462) mixed methods designs. Mason (2006) argues that: "social experience and lived realities are multi-dimensional" (p.10) and thus we need "a palette of methods" (p.14) from which to draw our research designs. She also argues that "Qualitative research 
has the explanatory edge precisely because it is concerned with explanation in a wider sense then measurement or causation" (Mason 2006, p.16, original emphasis). Jennifer Greene $(2006,2008,2009)$ notes the need to recognise and promote diversity in the Mixed Methods community and identifies socio-political commitments as an important element of a mixed methods approach to social inquiry. Donna Mertens $(2003,2007)$ has argued the need to develop a social justice agenda in Mixed Methods Research, including negotiating the purpose, access, and focus of any research study with the communities under investigation.

Thus there may be something of a difference emerging in the arguments advanced for developing the use of qualitative methods in MMR. For central policy-makers qualitative methods afford illuminative insight into the activities of the periphery of the social system which they are attempting to manage. For more independent and critical researchers qualitative approaches offer greater purchase on the complexities of social life, and greater opportunities to involve research participants in studies which may shape the conditions under which they live. It is in this context that the core strengths of qualitative research - the face-to-face contact that the researcher has with research participants - might be further developed, with the potential of a far greater role for research participants themselves being realised, via respondent validation, in the co-construction of research knowledge.

\section{Towards more democratic participation in mixed methods research designs}

One of the ironies of this situation, certainly with respect to the field of educational and social program evaluation from which much contemporary MMR activity seems to derive, is that evaluation as a field of study has long since raised and attempted to address questions of the role and power of the evaluator. As long ago as 1974, Barry MacDonald proposed a typology of what he termed Autocratic, Bureaucratic and Democratic Evaluation, whereby autocratic evaluation is aligned with the claimed independence and disinterest of science, bureaucratic evaluation is aligned with the service role performed by researchers in response to government contracts, and democratic evaluation is an aspirational activity designed to involve research respondents in constructing the evaluation agenda and to provide information for the widest possible public audience:

Autocratic evaluation is a conditional service to...government...It offers external validation of policy in exchange for compliance with its recommendations...the evaluator...acts as expert adviser...[ ]...Bureaucratic evaluation is an unconditional service to...government...The evaluator... acts as a management consultant...the report 
is owned by the bureaucracy and lodged in its files...[ ]...Democratic evaluation is an information service to the whole community about the characteristics of an educational program...The democratic evaluator recognises value pluralism and seeks to represent a range of interests...techniques of data gathering and presentation must be accessible to non-specialist audiences...

(MacDonald, 1974, reprinted 1987, pp. 44-45)

Around the same time Bob Stake (1975) introduced the idea of 'Responsive Evaluation', defined as follows:

An educational evaluation is responsive evaluation (1) if it orients more directly to program activities than to program intents, (2) if it responds to audience requirements for information, and (3) if the different value perspectives of the people at hand are referred to in reporting the success and failure of the program (p.11)

More recently Ernie House and Ken Howe (1999) have reviewed such ideas and others and proposed a 'Deliberative Democratic' approach to evaluation, arguing that evaluation studies should attend to the interests, values, and views of all stakeholders involved in the program or policy under review. Several other empowerment and participatory evaluation models have also been discussed in the literature (Fetterman, 2001; Whitmore, 1998). Thus it would seem important that contemporary versions of MMR attend as much to this heritage of ethical and methodological debate, as to the continuing arguments about what might or might not constitute a new paradigm.

Furthermore, ideas of engagement which underpin concepts such as democratic, responsive and deliberative approaches to evaluation, are not confined to the field of evaluation. Similar ideas are widely debated across the social sciences in discussions about new forms of knowledge production and knowledge transfer. It is now widely recognised from many different perspectives, including that of the empowerment of research subjects on the one hand, and also policy relevance and social utility on the other, that other voices must be heard in the debate over scientific quality and merit, particularly in applied, policy-oriented fields such as health and education. Thus for example Gibbons et al. (1994) distinguish between what they term 'Mode1' and 'Mode 2' knowledge. Mode 1 knowledge is broadly defined as scientific knowledge deriving from what might be termed the traditional academic disciplines. Mode 2 knowledge is defined more collaboratively and interactionally as deriving from and operating within "a context of application" (p. 3). Such knowledge is "transdisciplinary... [and] involves the close interaction of many actors throughout the process of knowledge production" (p. vii). In turn judgements of validity and scientific 
quality must be "determined by a wider set of criteria which reflects the broadening social composition of the review system" (Gibbons et al 1994 p.8).

The language employed by Gibbons et al. and the assumed context of operation very much reflects an engineering/technology-transfer type set of activities, but it also mirrors a far wider set of concerns with respect to re-defining the validity and social utility of research. There is a clear orientation towards the co-creation of knowledge through collaborative, contextualised, problem-solving action - rather than the discovery of knowledge through centralised, 'expert' investigation (mixed method or otherwise) which then gets presented to policymakers and in due course disseminated to 'practitioners' or other 'research users' at the periphery. Ideas about the co-creation of knowledge clearly link with deliberative and empowerment models of evaluation. The concept of 'mode 2 knowledge' also reflect something of the arguments around indigenous knowledge (Smith, 2005), the problem of 'othering' research respondents (Ellis, 1995), and the many articulations and interrogations of how to identify and represent different 'voices' in research (e.g. Alcoff, 1991; Appadurai, 2006; Jackson \& Mazzei, 2009). Such arguments, coalescing into a diverse, contested, but nevertheless highly provocative and promising constellation of issues around the validity, utility and ethics of social research provide a substantial intellectual reservoir on which mixed methods research can draw. Some references to congruent approaches such as action research and participatory action research can be found in the MMR literature (e.g. Christ, 2010; Mertens et al., 2010) and my argument is that these could be strengthened by further engagement with the wider knowledge generation literature. In particular there is a clear opportunity for MMR to incorporate the practice of respondent validation into definitions of triangulation. The research respondent must also be included in the 'multiple observers' of Denzin's (1970) initial articulation of triangulation.

As MMR has sought to become established as a field, important elements in the debate seem to have ignored the democratic accountability arguments of evaluation, while at the same time also avoiding engagement with wider social scientific arguments about transdisciplinary and collaborative knowledge generation. In the above quotes from Caracelli, and other significant position papers in the field (e.g. Johnson, et al., 2007; Morgan, 2007), there is no reflection on the power relations at work in evaluative research designs or similar investigation of social interventions. The current manifestation of MMR has come of age (and my guess is that this is no coincidence) in an era of social program intervention, so- 
called evidence-based policy and practice, and evaluations which are supposed to 'prove' what works. As such, it seems to be completely taken for granted by significant sections of the new MMR 'third community' that we can assume the enduring power of science (i.e., the production of expert research knowledge) along with a centre-periphery model of research production, policy development and policy evaluation. Yet it is at least arguable that such a model of policy development and implementation locates agency in government and professional bureaucracies rather than communities.

Many recent discussions of quality in qualitative research revolve around issues of engagement, deliberation, ethical process and responsiveness to participant agendas, along with the need to maintain a critical perspective on both the topic at hand and the power of particular forms of knowledge (Lincoln, 1995; Schwandt, 1996; Lather, 2004; 2010, Smith, 2005). It is these strengths of a qualitative approach that should be privileged in any discussion of their inclusion in a Mixed Methods design, and in turn they should be used to further connect Mixed Methods Research with the democratic engagement of research participants. The emergent third community, if such it is, must engage with ethical and political issues in order to become a reflexive methodological community, and include research respondents in the definition of such a community. A much more extensive and principled use of qualitative methods and values in Mixed Method Research designs, linked to engaging the views of research participants in constructing the agenda and reports of mixed methods research, would be one way of achieving this. Morgan's (2007) identification of "the abductive-intersubjective-transferable aspects of our research" (p. 73) provides an important prompt for further development of MMR if the community conducting 'our research' is seen to include the full range of research participants.

Mixed method research designs rest on the idea of triangulation, on the perceived strengths of comparing, contrasting and attempting to integrate different sorts of data. Denzin's $(1970,1978)$ original formulation of triangulation included a role for multiple investigators as well as multiple methods. Such multiple investigators can and should include research respondents themselves. Moreover such involvement should not simply be about attempting to produce a more valid account for other, potentially more powerful research users - for example central policy makers. Rather, the aspiration must be to link triangulation and respondent validation to democratic engagement and participation in program development and the use of research findings at local level. In this respect the process of 
producing and using new social knowledge is as important as the knowledge itself. Respondent validation is no panacea, and it is in no sense a straightforward process. Quite the reverse, it is uncomfortable and challenging. But it is an important potential corrective to the ambitions and taken-for-granted assumptions of social program intervention. Identifying the important research questions to be pursued and discussing emergent findings with the communities under investigation should produce better research, as well as developing community capacity to engage with research effectively.

Comment: In your conclusion, I would ask that you come back to the issue of triangulation that you started with and tie the linkage between triangulation -respondent validation and democratic participation together. 


\section{$\underline{\text { References }}$}

Alcoff L (1991) 'The Problem of Speaking for Others' Cultural Critique, Winter 1991-92, pp. 5-32

Appadurai A. (2006) 'The right to research' Globalisation, Societies and Education 4, 2, 167177

Becker H, Geer B, Hughes E. and Strauss A. (1961) Boys in White: student culture in medical school New Brunswick, Transactions Publishers

Bergman M. (Ed. 2008) Advances in Mixed Methods Research: theories and applications London, Sage

Bloor M. (1978) 'On the analysis of observational data: a discussion of the worth and uses of inductive techniques and respondent validation' Sociology 12, 3, 545-552

Blumer H. (1969) Symbolic Interactionism: perspective and method University of California Press, Berkeley.

Bryman A. (1988) Quantity and Quality in Social Research, London, Unwin Hyman

Cabinet Office (2003) Quality in Qualitative Evaluation: a framework for assessing research evidence London, Cabinet Office

Caracelli V. (2006) 'Enhancing the policy process through the use of ethnography and other study frameworks: a mixed methods strategy’ Research in the Schools 13, 1, 84-92

Creswell J. (2003, $2^{\text {nd }}$ edition) Research Design: qualitative, quantitative and mixed methods approaches Sage

Creswell J. (2010) 'Mapping the Developing Landscape of Mixed Methods Research' in Tashakkori A. and Teddlie C. (Eds. $2^{\text {nd }}$ Edition) Mixed Methods in Social and Behavioral Research Sage

Creswell J, Klassen A, Plano Clark V. and Smith K. (2011) Best Practice for Mixed Methods Research in the Health Sciences Office of Behavioral and Social Sciences Research (OBSSR), National Institutes of Health (NIH)

Creswell J. and Plano Clark V. (2007) Designing and Conducting Mixed Methods Research, Sage

Christ T. (2009) 'Designing, teaching and evaluating two complementary mixed methods research courses' Journal of Mixed Methods Research 3, 4, 292-325

Christ T. (2010) 'Teaching Mixed Methods and Action Research: pedagogical, practical and evaluative considerations' in Tashakkori A. \& Teddlie C. (Eds) Handbook of Mixed Methods in Social and Behavioural Research, second edition Sage

Denscombe M. (2008) 'Communities of Practice: A research paradigm for the mixed methods approach’ Journal of Mixed Methods Research, 2, 3, 270-283 
Denzin N. (1970, $1978 \& 1989: 1^{\text {st }}, 2^{\text {nd }}$ and $3^{\text {rd }}$ editions) The Research Act Prentice Hall, New Jersey

Denzin N. (2010) The Qualitative Manifesto: a call to arms Left Coast Press

Duncier M. (2001) 'On the evolution of Sidewalk' in Emerson R. (ed) Contemporary Field Research: perspectives and formulations Long Grove Ill, Waveland Press

Ellis C. (1995) 'Emotional and ethical quagmires in returning to the field' Journal of Contemporary Ethnography 24, 1, 68-98

Fetterman D. (2001) Foundations of Empowerment Evaluation Thousand Oaks, Sage.

Fielding N. and Fielding J. (1986) Linking Data Beverley Hills, Sage

Gibbons M, Limoges C, Nowotny H, Schwartzman S, Scott P and Trow M (1994) The New Production of Knowledge Thousand Oaks, Sage

Giddings L. (2006) 'Mixed methods research: positivism in drag?' Journal of Research in Nursing 11, 3, 195-203

Greene J. (2006) 'Toward a Methodology of Mixed Methods Social Inquiry' Research in the Schools 13, 1, 93-98

Greene J. (2007) Mixed methods in Social Inquiry San Francisco, Jossey-Bass

Greene J. (2008) ‘Is Mixed Methods Social Inquiry a Distinctive Methodology?' Journal of Mixed Methods Research, 2, 1, 7-22

Greene J. (2009) 'Meaningfully engaging with difference through mixed methods educational evaluation' in Ryan K. and Cousins B. (Eds) Sage Handbook of Educational Evaluation Thousand Oaks, Sage

Greene J. et. al (1989) 'Toward a Conceptual Framework for Mixed Methods Evaluation Designs' Educational Evaluation and Policy Analysis 11, 3, 255-274

Hesse-Biber S. (2010a) 'Qualitative approaches to mixed methods practice' Qualitative Inquiry 16, 6, 455-468

Hesse-Biber S. (2010b) 'Feminist Approaches to Mixed Methods Research: linking theory and praxis' in Tashakkori A. and Teddlie C. (Eds. $2^{\text {nd }}$ Edition) Mixed Methods in Social and Behavioral Research Sage

Harrits G. (2011) 'More Than Method? A discussion of paradigm differences within mixed methods research' Journal of Mixed Methods Research 5, 2, 150-166

House E. \& Howe K. (1999) Values in Evaluation and Social Research Thousand Oaks, Sage. 
Jackson A. \& Mazzei L. (Eds 2009) Voice in Qualitative Inquiry London, Routledge

Jang E, McDougall D, Pollon D, Herbert M. and Russell P. (2008) 'Integrative Mixed Methods Data Analytic Strategies in Research on School Success in Challenging Circumstances' Journal of Mixed Methods Research 2, 3, 221-247

Johnson R. B. et. al. (2007) 'Toward a Definition of Mixed Methods Research' Journal of Mixed Methods Research, 1, 2, 112-133

Lather P. (2004) 'This IS your father's paradigm: government intrusion and the case of qualitative research in education' Qualitative Inquiry 10, 1, 15-34

Lather P. (2010) Engaging Science Policy from the Side of the Messy New York, Peter Lang

Lincoln Y. (1995) 'Emerging criteria for quality in qualitative and interpretive research' Qualitative Inquiry 1, 3, 275-289

Lincoln Y. and Guba E. (1985) Naturalistic Inquiry Newbury Park, Sage

MacDonald B. (1974) 'Evaluation and the Control of Education' reprinted in Murphy R. and Torrance H. (Eds 1987) Evaluating Education: issues and methods London, Harper \& Row, and H. Torrance (Ed. 2010) Qualitative Research Methods in Education, Thousand Oaks, Sage

Mason J. (2006) 'Mixing methods in a qualitatively driven way' Qualitative Research 6, 1, 925

Mathison S. 'Why Triangulate?' Educational Researcher March 1988, 13-17

Mertens D. (2003) 'Mixed Methods and the Politics of Human Research: The Transformative-Emancipatory Perspective' in Tashakkori and Teddlie op. cit

Mertens D. (2007) 'Transformative Paradigm: Mixed Methods and Social Justice' Journal of Mixed Methods Research, 1, 3, 212-225

Mertens D. Bledsoe K, Sullivan M, and Wilson A. (2010) 'Utilisation of Mixed Methods for Transformative Purposes' in Tashakkori A. \& Teddlie C. (Eds) Handbook of Mixed Methods in Social and Behavioural Research, second edition Sage

Meyer J. (2005) 'Health Research' in Somekh B. \& Lewin C. (Eds) Research methods in the social sciences Sage

Morgan D. (2007) 'Paradigms lost and paradigms regained: methodological implications of combining qualitative and quantitative methods' Journal of Mixed Methods Research 1, 1, 48-79

National Research Council (2002) Scientific Research in Education, Washington, Author 
Niglas K. (2010) 'The Multidimensional Model of Research Methodology: an integrated set of continua' in Tashakkori A. and Teddlie C. (Eds. $2^{\text {nd }}$ Edition) Mixed Methods in Social and Behavioral Research Sage

Patton M. (1980) Qualitative Evaluation Methods Sage

Schwandt T. (1996) 'Farewell to criteriology' Qualitative Inquiry 2, 1, 58-72

Smith L. (2005) 'On tricky ground: researching the native in the age of uncertainty' in Denzin N. \& Lincoln Y. (Eds) The Sage Handbook of Qualitative Research: third edition Thousand Oaks, Sage

Stake R. (1975) 'Program evaluation, particularly responsive evaluation' paper presented to 'New Trends in Evaluation' conference, Goteborg University; reprinted in Dockrell W. \& Hamilton D. (Eds 1980) Rethinking Educational Research London, Hodder \& Stoughton

Tashakkori A. \& Teddlie C. (2003, Eds) Handbook of Mixed Methods in Social and Behavioural Research Sage

Tashakkori A. \& Teddlie C. (2010, Eds) Handbook of Mixed Methods in Social and Behavioural Research, second edition Sage

Teddlie C. \& Tashakkori A. (2009) Foundations of Mixed Methods Research Sage

Torrance H. (2011) 'Qualitative Research, Science and Government: Evidence, Criteria, Policy and Politics' in Denzin N. and Lincoln Y. (2011) Handbook of Qualitative Research: $4^{\text {th }}$ edition Sage

Walker R. (1974) 'The Conduct of Educational Case Study: ethics, theory and procedures' in MacDonald B. and Walker R. (eds) Innovation, Evaluation, Research and the Problem of Control, University of East Anglia SAFARI Papers; reprinted in H. Torrance (Ed. 2010) Qualitative Research Methods in Education, Thousand Oaks, Sage

Whitmore E. (Ed. 1998) Understanding and Practicing Participatory Evaluation: New Directions for Evaluation No. 80 San Francisco, Jossey-Bass

Whyte W. F. (1943) Street Corner Society Chicago, University of Chicago Press 